\title{
Association between Beta-Fibrinogen C148T Gene Polymorphism and Risk of Ischemic Stroke in a North Indian Population: A Case-Control Study
}

\author{
Amit Kumar Shubham Misra Pradeep Kumar Ram Sagar \\ Kameshwar Prasad
}

Department of Neurology, Neurosciences Centre, All India Institute of Medical Sciences, New Delhi, India

\section{Key Words}

Ischemic stroke · Polymorphisms · Endothelial nitric oxide synthase $\cdot$ North India ·

Cerebrovascular disease

\begin{abstract}
Background and Purpose: Stroke is a multifactorial disease influenced by both genetic and environmental factors. The aim of this case-control study was to determine the association between $\beta$-fibrinogen C148T ( $r$ 1800787) gene polymorphism and susceptibility to ischemic stroke (IS) in a North Indian population. Methods: In the present case-control study, genotyping was performed using the PCR-RFLP (polymerase chain reaction-restriction fragment length polymorphism) method on 250 IS patients and 250 age- and sex-matched controls. Frequency distributions of genotypes and alleles were compared between the cases and controls by conditional logistic regression. Results: Hypertension, diabetes, dyslipidemia, low socioeconomic status, and family history of stroke were found to be independent risk factors for IS. The mean age of the cases and controls was $52.83 \pm 12.59$ and $50.97 \pm 12.70$ years, respectively. Multivariate logistic regression analysis showed an independent association between $\beta$-fibrinogen C148T ( $r$ 1800787) polymorphism and risk of IS in dominant (OR $=2.19$; $95 \%$ CI 1.23-3.90; $p=0.007)$ and allelic $(O R=1.66 ; 95 \%$ CI 1.19-2.33; $p=0.002)$ models. Based on the Trial of Org 10172 in Acute Stroke Treatment (TOAST) classification, an independent association of small vessel disease with risk of IS was observed in the dominant (OR $=2.09$; 95\% CI 1.10-3.96; $p=0.02$ ) and allelic (OR $=1.75 ; 95 \%$ CI 1.12-2.75; $p=0.01)$ models, and a significant association of cardioembolic stroke with risk of IS was seen in the allelic model (OR $=2.11 ; 95 \%$ CI 1.07-4.17; $p=0.02$ ). All the genotype frequencies observed were in accordance with Hardy-Weinberg equilibrium in both cases and controls. Conclusion: The findings of the
\end{abstract}


Kumar et al.: Association between Beta-Fibrinogen C148T Gene Polymorphism and

Risk of Ischemic Stroke in a North Indian Population: A Case-Control Study

present study suggest that polymorphism in the C148T position of the $\beta$-fibrinogen gene might be a risk factor for IS mainly for the small vessel disease stroke subtype in a North Indian population. Further, large prospective studies are required to confirm these findings.

(C) 2016 S. Karger AG, Basel

\section{Introduction}

Stroke is known to be a major, devastating neurological disorder having a high mortality rate. By the year 2030, it has been estimated that the death toll due to stroke will rise to 12 million, with only 70 million stroke survivors and more than 200 million disability-adjusted life years lost worldwide [1, 2]. Ischemic stroke (IS), which accounts for $85 \%$ of the stroke subtypes, is only the second most common cause of mortality across the globe after ischemic heart disease [3]. Stroke has been known to result from a combination of various vascular, environmental, and genetic factors [4]. Hereditability estimates of IS vary from 17 to $38 \%$.

Plasma fibrinogen is known to be a risk factor for stroke and myocardial infarction [5]. It is a pivotal constituent of the coagulation cascade and a crucial determinant of blood viscosity and flow. Fibrinogen is located on the long arm of chromosome number 4, which encodes $\alpha$-, $\beta$-, and $\gamma$-chains. It is encoded by 3 separate genes in a cluster of $50 \mathrm{~kb}$ [6]. Synthesis of the $\beta$-polypeptide chain is the rate-limiting step in fibrinogen formation which is regulated by a $\beta$-fibrinogen promoter [7]. Several studies in the past have described an association between plasma fibrinogen levels and stroke, coronary heart disease, and carotid atherosclerosis. Previous studies have shown that the C148T polymorphism of $\beta$-fibrinogen is associated with an increased plasma fibrinogen level in both men and women [8-10]. A meta-analysis of 20 studies in a Chinese population including 2,561 cases and 2,402 controls has shown a significant association between C148T gene polymorphism and risk of IS with a pooled OR of 1.56 (95\% CI 1.39-1.75) [11]. However, these studies were confined to a single population; therefore, studies with large sample sizes from different populations are required. The present study was undertaken to establish a firm relationship between C148T gene polymorphism of $\beta$-fibrinogen and risk of IS in a North Indian population.

\section{Subjects and Methods}

\section{Study Participants}

The present study was completed at the Department of Neurology, Neurosciences Centre, All India Institute of Medical Sciences, New Delhi, India. The study design was a hospital-based case-control study, and it was completed in a period of 2 years (November 2012 to October 2014). A total of 450 patients were screened for eligibility criteria. Patients with a history of autoimmune disease, transient ischemic attack, rheumatologic disease, any acute or chronic infection, hemorrhagic stroke proven by computed tomography or magnetic resonance imaging, and stroke due to surgery or pregnancy were excluded. The World Health Organization definition of stroke was used. Age- and sex-matched healthy individuals were used as controls in the study. Stroke-free status of the controls was assessed by the Questionnaire for Verifying Stroke-Free Status (QVSFS) [12]. Informed consent was obtained from all subjects before data collection. The study was approved by the local institutional ethics committee.

Detailed history-taking and a clinical evaluation were carried out. IS was further classified using the Trial of Org 10172 in Acute Stroke Treatment (TOAST) criteria [13]. The National Institutes of Health Stroke Scale (NIHSS) was used for determination of clinical severity on the day of admission. Definitions of variables were modified from the study protocol published by Kumar et al. [14]. 
Fig. 1. RFLP gel image of $\beta$-fibrinogen C148T polymorphism. Loading order: $\mathrm{M}=100 \mathrm{bp}$ Ladder. Lanes 1, 2, 4, 6, 7, and 13: C/T genotype (heterozygous genotype). Lanes 3, 5, 8-12, and 14-19: T/T genotype (wild type).
Kumar et al.: Association between Beta-Fibrinogen C148T Gene Polymorphism and Risk of Ischemic Stroke in a North Indian Population: A Case-Control Study

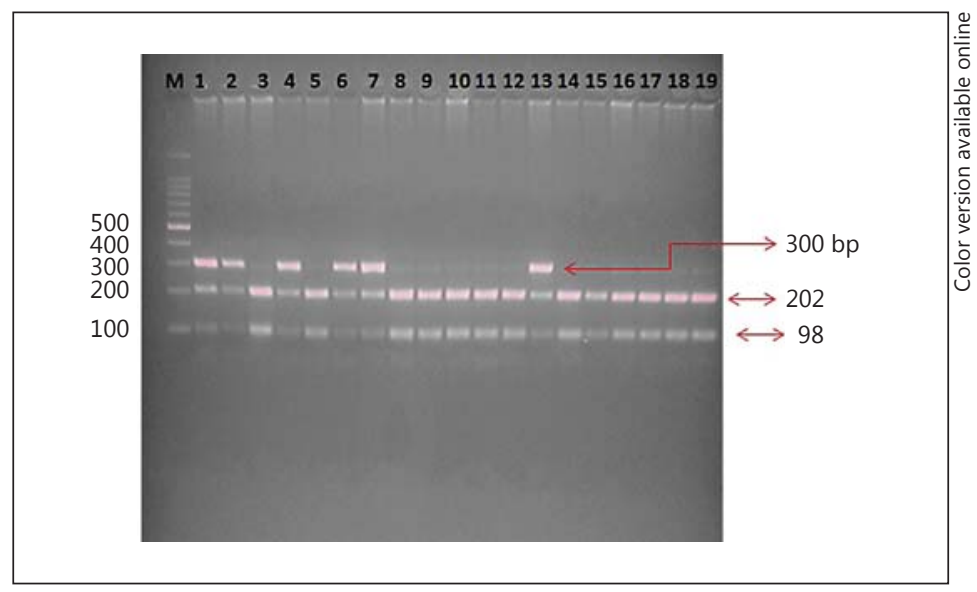

Laboratory Investigations

Single-time 1-teaspoon (4-ml) blood samples were taken in an ethylenediaminetetraacetic acid vial from the patients and controls. Total genomic DNA was isolated from whole blood with the standard phenolchloroform method.

\section{Genotype Determination}

The genotypes of the $\beta$-fibrinogen C148T gene were detected with the PCR-RFLP (polymerase chain reaction-restriction fragment length polymorphism) technique. The primers were designed for the single nucleotide polymorphism using the Primer3 online tool (http://bioinfo.ut.ee/primer3-0.4.0/). The $\beta$-fibrinogen C148T region was amplified using the primers forward $5^{\prime}$-CCTAACTTCCCATCATTTTGTC- $3^{\prime}$ and reverse $5^{\prime}$-ATGGTTTTAAGTTTGTGGAAGC- $3^{\prime}$ in a T100 thermal cycler (Bio-Rad). The primers were synthesized by Imperial Life Sciences (Gurgaon, India) under standard conditions. The conditions for amplification were as follows: an initial melting step of $4 \mathrm{~min}$ at $94^{\circ} \mathrm{C}$, followed by 35 cycles of $30 \mathrm{~s}$ of denaturation at $94^{\circ} \mathrm{C}, 30 \mathrm{~s}$ of annealing at $56.7^{\circ} \mathrm{C}, 45 \mathrm{~s}$ of extension at $72^{\circ} \mathrm{C}$, and a final elongation step of $7 \mathrm{~min}$ at $72^{\circ} \mathrm{C}$. Genotyping was performed by digesting the PCR products using the HindIII restriction enzyme and incubation at $37^{\circ} \mathrm{C}$ overnight. After amplification and digestion, the products were confirmed by agarose gel electrophoresis. Bands of 202 and 300 bp were observed after digestion, as seen through the UV transilluminator (fig. 1).

\section{Statistical Analysis}

The $\chi^{2}$ test was used to determine whether the allelic frequencies were in accordance with HardyWeinberg equilibrium or not. Conditional logistic regression analysis was used to estimate ORs and $95 \%$ CIs for the strength of association between $\beta$-fibrinogen C148T polymorphism and risk of IS. Multivariate logistic regression was used to control for the confounding effects of demographic and risk factor variables. Tests were considered significant at $\mathrm{p}<0.05$. The data were analyzed using Stata version 13.0 (StataCorp, College Station, Tex., USA).

\section{Results}

After screening 450 stroke cases, 250 IS cases were included in the study. For the control group, 393 people were screened and 250 age- and sex-matched controls were recruited to the study. The mean age of the IS patients was $52.8 \pm 12.5$ years, and that of the control group was $50.9 \pm 12.7$ years; both groups consisted of 203 males and 47 females. There was no statistical difference in age between the cases and controls ( $p>0.05)$. The demographic and risk factor variables of the IS patients and controls are presented in table 1 . The control group was matched for age and sex, and, as expected, hypertension (cases vs. controls: 58.4 vs. 
Kumar et al.: Association between Beta-Fibrinogen C148T Gene Polymorphism and Risk of Ischemic Stroke in a North Indian Population: A Case-Control Study

Table 1. Demographic and risk factor variables for IS patients and control subjects

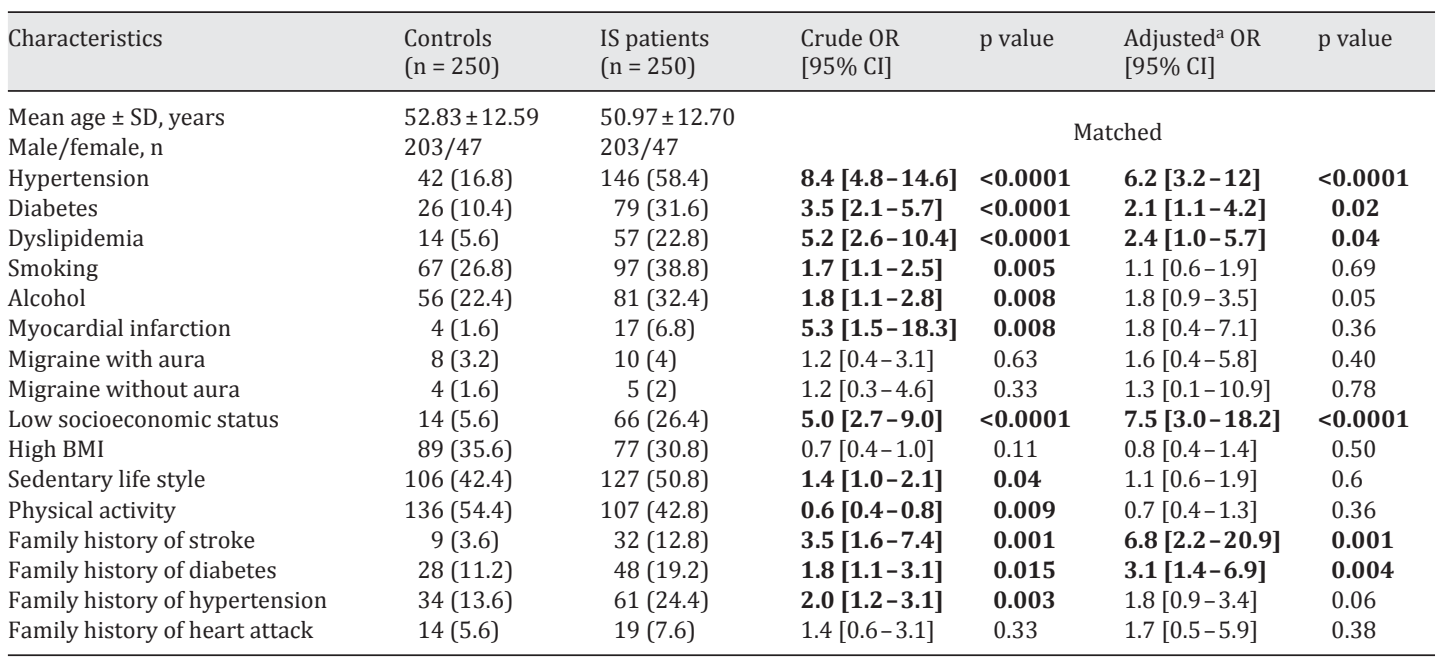

Values are presented as n (\%) unless specified otherwise. Conditional logistic regression analysis. Boldface denotes significance $(\mathrm{p}<$ 0.05). IS = Ischemic stroke; BMI = body mass index; $\mathrm{OR}=$ odds ratio; $\mathrm{CI}=$ confidence interval; $\mathrm{SD}=$ standard deviation. ${ }^{\mathrm{a}}$ Adjusted variables include hypertension, diabetes, dyslipidemia, smoking, family history of stroke, alcohol, sedentary lifestyle, and low socioeconomic status.

$16.8 \%$ ), diabetes (cases vs. controls: 31.6 vs. $10.8 \%$ ), and dyslipidemia (cases vs. controls: 22.8 vs. $5.6 \%)$ were found significantly more often in cases than in controls $(p<0.05)$.

All genotype and allelic frequencies were in Hardy-Weinberg equilibrium in both IS patients and controls. The genetic analysis of $\beta$-fibrinogen gene polymorphism was conducted on all 250 IS cases and 250 age- and sex-matched controls; the results are summarized in tables 2 and 3. The adjusted conditional logistic regression analysis showed a significant association of $\beta$-fibrinogen gene polymorphism with risk of IS in the dominant (OR $=2.19 ; 95 \%$ CI 1.23-3.90; $\mathrm{p}=0.007)$ and allelic (OR $=1.66 ; 95 \%$ CI 1.19-2.33; $\mathrm{p}=0.002)$ models.

In the subgroup analysis as per the TOAST classification, an independent association with small vessel disease was observed in the dominant (OR $=2.09 ; 95 \%$ CI $1.10-3.96 ; p=0.02$ ) and allelic (OR $=1.75 ; 95 \% \mathrm{CI} 1.12-2.75 ; \mathrm{p}=0.01)$ models. A significant association was also observed with the cardioembolic subtype of IS in the allelic model (OR $=2.11$; 95\% CI 1.074.17; $\mathrm{p}=0.02$ ).

\section{Discussion}

The present case-control study suggests that polymorphism in the C148T position of the $\beta$-fibrinogen gene is associated with risk of IS in a North Indian population. An elevated level of $\beta$-fibrinogen has been found to be associated with an independent risk of stroke, venous thrombosis, ischemic heart disease, and peripheral artery disease $[15,16]$. Fibrinogen is synthesized in the liver and is involved in blood coagulation. On activation, it is converted into fibrin and forms thrombi with subsequent hemostasis. It is located on chromosome 4, consisting of $\alpha-, \beta-$, and $\gamma$-chains located in a 50 -kb region. Although mRNA is independently synthesized for each of the chains, transcriptional regulation of these genes is known to be closely related.

G-A substitution in the promoter region of $\beta$-fibrinogen has been found to be associated with an increase in plasma fibrinogen levels $[17,18]$. One study demonstrated that the $\beta$-fibrinogen 148 TT genotype was associated with genetic risk factors for carotid atherosclerosis [19]. A meta-analysis which included 12 case-control studies involving 1,536 cases and 1,329 control subjects demonstrated that 148 CT polymorphism of the $\beta$-fibrinogen gene is a 
Kumar et al.: Association between Beta-Fibrinogen C148T Gene Polymorphism and

Risk of Ischemic Stroke in a North Indian Population: A Case-Control Study

Table 2. Genotype and allelic frequencies of $\beta$-fibrinogen C148T gene polymorphism in IS patients and controls

\begin{tabular}{|c|c|c|c|c|c|c|c|c|c|c|}
\hline \multirow[t]{2}{*}{ Group } & \multirow{2}{*}{$\begin{array}{l}\text { Subjects, } \\
\mathrm{n}\end{array}$} & \multicolumn{3}{|c|}{ Genotypes, n (\%) } & \multirow{2}{*}{$\begin{array}{l}\text { HWE } \\
\text { p value }\end{array}$} & \multicolumn{2}{|l|}{ Allele, n (\%) } & \multicolumn{3}{|c|}{ Allele C vs. T } \\
\hline & & $\mathrm{CC}$ & $\mathrm{CT}$ & TT & & $\mathrm{C}$ & $\mathrm{T}$ & OR & $95 \% \mathrm{CI}$ & $\mathrm{p}$ value \\
\hline Controls & 250 & $188(75.2)$ & $56(22.4)$ & $6(2.4)$ & 0.45 & $432(86.4)$ & 68 (13.6) & & & \\
\hline IS & 250 & $153(61.2)$ & $90(36)$ & $7(2.8)$ & 0.14 & $396(79.2)$ & $104(20.8)$ & 1.66 & $1.19-2.33$ & 0.002 \\
\hline LVD & 107 & $67(62.6)$ & $39(36.4)$ & $1(0.94)$ & 0.06 & $173(80.8)$ & 41 (19.1) & 1.50 & $0.98-2.30$ & 0.058 \\
\hline SVD & 83 & $50(60.2)$ & $30(36.1)$ & $3(3.7)$ & 0.55 & $130(78.3)$ & 36 (21.7) & 1.75 & $1.12-2.75$ & 0.01 \\
\hline $\mathrm{CE}$ & 26 & $15(57.7)$ & 9 (34.6) & $2(7.7)$ & 0.69 & $39(75)$ & $13(25)$ & 2.11 & $1.07-4.17$ & 0.02 \\
\hline Others & 34 & $21(61.8)$ & $12(35.3)$ & $1(2.9)$ & 0.64 & $54(79.4)$ & $14(20.6)$ & 1.64 & $0.86-3.12$ & 0.12 \\
\hline
\end{tabular}

$\mathrm{CI}=$ Confidence interval; $\mathrm{OR}=$ odds ratio; $\mathrm{C}=$ cytosine; $\mathrm{CC}=$ cytosine cytosine; $\mathrm{T}=$ thymine; $\mathrm{CT}=$ cytosine thymine; $\mathrm{TT}=$ thymine thymine; IS = Ischemic stroke; LVD = large vessel disease; SVD = small vessel disease; CE = cardioembolic; HWE = Hardy-Weinberg equilibrium. Boldface denotes significance $(\mathrm{p}<0.05)$.

Table 3. Association between $\beta$-fibrinogen C148T gene polymorphism and risk of IS

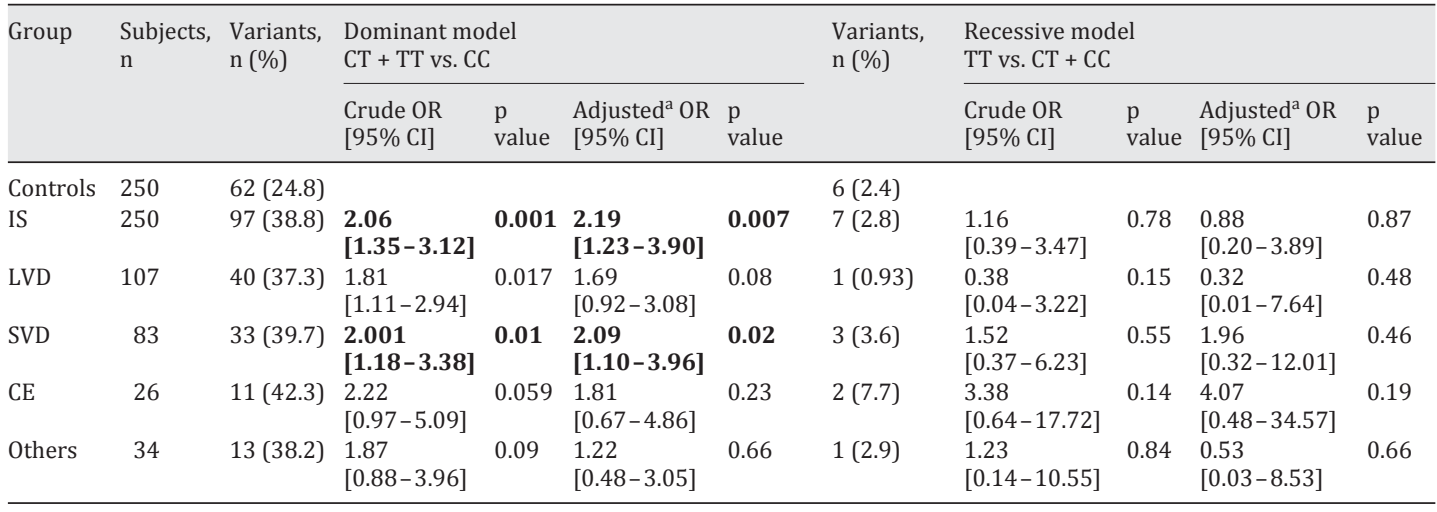

$\mathrm{CI}=$ Confidence interval $\mathrm{OR}=$ odds ratio $\mathrm{C}=$ cytosine $\mathrm{CC}=$ cytosine cytosine $\mathrm{T}=$ thymine $\mathrm{CT}=$ cytosine thymine; $\mathrm{TT}=$ thymine thymine; IS = ischemic stroke; LVD = large vessel disease; SVD = small vessel disease; CE = cardioembolic. Boldface denotes significance $(\mathrm{p}<0.05) .{ }^{a}$ Adjusted analysis was done by adjusting for hypertension, diabetes, dyslipidemia, smoking, family history of stroke, alcohol, sedentary lifestyle, and low economic status.

susceptibility marker for risk of IS [20]. Another meta-analysis which involved 32 independent studies with 4,311 cases and 4,124 controls demonstrated that 148 CT polymorphism of $\beta$-fibrinogen contributes to susceptibility to IS [11].

The findings of the present study also confirm a significant association between the $T$ allele of the $\beta$-fibrinogen gene and susceptibility to IS mainly in the small vessel subtype of stroke. Multivariate logistic regression analysis also observed an independent association between 148 CT polymorphism and risk of IS in the dominant model of inheritance. The analysis based on the TOAST classification demonstrated that this association was mainly with the small vessel subtype of stroke. These findings are consistent with those of a study which observed that polymorphism in the $\beta$-fibrinogen gene is associated with risk of the small vessel subtype of stroke [21].

\section{Conclusion}

The findings of the present study suggest that polymorphism in the C148T position of the $\beta$-fibrinogen gene might be a risk factor for IS mainly for the small vessel disease stroke subtype in a North Indian population. Further, large prospective studies are required to confirm these findings. 
Kumar et al.: Association between Beta-Fibrinogen C148T Gene Polymorphism and

Risk of Ischemic Stroke in a North Indian Population: A Case-Control Study

\section{Acknowledgment}

We acknowledge the technical assistance of staff members of the Neurology Department of the All India Institute of Medical Sciences, New Delhi. We also thank all patients and control participants for providing blood samples.

We would like to thank the Department of Biotechnology, Government of India, for providing resources through Programme Support in Stroke - Phase II projects for successfully completing this study (Indian Council of Medical Research, New Delhi, India; Ref. No. 5/4-5/76/Neuro/2012/NCD-1).

\section{Disclosure Statement}

The authors declare that no competing interests exist.

\section{References}

1 Feigin VL, Forouzanfar MH, Krishnamurthi R, Mensah GA, Connor M, Bennett DA, et al: Global and regional burden of stroke during 1990-2010: findings from the Global Burden of Disease Study 2010. Lancet 2014;383: 245-254.

2 Strong K, Mathers C, Bonita R: Preventing stroke: saving lives around the world. Lancet Neurol 2007;6:182187.

3 Della-Morte D, Guadagni F, Palmirotta R, Testa G, Caso V, Paciaroni M, et al: Genetics of ischemic stroke, strokerelated risk factors, stroke precursors and treatments. Pharmacogenomics 2012;13:595-613.

4 Hassan A, Markus HS: Genetics and ischaemic stroke. Brain J Neurol 2000;123:1784-1812.

5 Maresca G, Di Blasio A, Marchioli R, Di Minno G: Measuring plasma fibrinogen to predict stroke and myocardial infarction: an update. Arterioscler Thromb Vasc Biol 1999;19:1368-1377.

6 Kant JA, Fornace AJ, Saxe D, Simon MI, McBride OW, Crabtree GR: Evolution and organization of the fibrinogen locus on chromosome 4: gene duplication accompanied by transposition and inversion. Proc Natl Acad Sci USA 1985;82:2344-2348.

7 Roy SN, Mukhopadhyay G, Redman CM: Regulation of fibrinogen assembly. Transfection of Hep G2 cells with $B \beta$ cDNA specifically enhances synthesis of the three component chains of fibrinogen. J Biol Chem 1990;265: 6389-6393.

8 Papageorgiou N, Tousoulis D, Siasos G, Stefanadis C: Is fibrinogen a marker of inflammation in coronary artery disease? Hellenic J Cardiol 2010;51:1-9.

9 van 't Hooft FM, von Bahr SJ, Silveira A, Iliadou A, Eriksson P, Hamsten A: Two common, functional polymorphisms in the promoter region of the $\beta$-fibrinogen gene contribute to regulation of plasma fibrinogen concentration. Arterioscler Thromb Vasc Biol 1999;19:3063-3070.

10 Tybjaerg-Hansen A, Agerholm-Larsen B, Humphries SE, Abildgaard S, Schnohr P, Nordestgaard BG: A common mutation $(G-455 \rightarrow A)$ in the $\beta$-fibrinogen promoter is an independent predictor of plasma fibrinogen, but not of ischemic heart disease. A study of 9,127 individuals based on the Copenhagen City Heart Study. J Clin Invest 1997; 99:3034-3039.

11 Wu G, Cai H, Cai H, Chen Z, Tan L, Qi H, et al: Effect of the -148C/T, 448G/A, and -854G/A polymorphisms of the $\beta$-fibrinogen gene on the risk of ischemic stroke in Chinese population. J Stroke Cerebrovasc Dis 2015;24: 1577-1590.

12 Jones WJ, Williams LS, Meschia JF: Validating the Questionnaire for Verifying Stroke-Free Status (QVSFS) by neurological history and examination. Stroke 2001;32:2232-2236.

13 Adams HP, Bendixen BH, Kappelle LJ, Biller J, Love BB, Gordon DL, et al: Classification of subtype of acute ischemic stroke. Definitions for use in a multicenter clinical trial. TOAST. Trial of Org 10172 in Acute Stroke Treatment. Stroke 1993;24:35-41.

14 Kumar A, Sagar R, Kumar P, Sahu JK, Grover A, Srivastava AK, et al: Identification of genetic contribution to ischemic stroke by screening of single nucleotide polymorphisms in stroke patients by using a case control study design. BMC Neurol 2013;13:136.

15 Fuss C, Palmaz JC, Sprague EA: Fibrinogen: structure, function, and surface interactions. J Vasc Interv Radiol 2001;12:677-682.

16 Lee AJ, Lowe GD, Woodward M, Tunstall-Pedoe H: Fibrinogen in relation to personal history of prevalent hypertension, diabetes, stroke, intermittent claudication, coronary heart disease, and family history: the Scottish Heart Health Study. Br Heart J 1993;69:338-342.

17 Iacoviello L, Vischetti M, Zito F, Benedetta Donati M: Genes encoding fibrinogen and cardiovascular risk. Hypertension 2001;38:1199-1203. 
Kumar et al.: Association between Beta-Fibrinogen C148T Gene Polymorphism and Risk of Ischemic Stroke in a North Indian Population: A Case-Control Study

18 Wypasek E, Stepien E, Kot M, Plicner D, Kapelak B, Sadowski J, et al: Fibrinogen beta-chain -C148T polymorphism is associated with increased fibrinogen, C-reactive protein, and interleukin-6 in patients undergoing coronary artery bypass grafting. Inflammation 2012;35:429-435.

19 Schmidt H, Schmidt R, Niederkorn K, Horner S, Becsagh P, Reinhart B, et al: $\beta$-Fibrinogen gene polymorphism $\left(\mathrm{C}_{148} \rightarrow \mathrm{T}\right)$ is associated with carotid atherosclerosis: results of the Austrian Stroke Prevention Study. Arterioscler Thromb Vasc Biol 1998;18:487-492.

20 Zhang XF, Luo TY: Association between the FGB gene polymorphism and ischemic stroke: a meta-analysis. Genet Mol Res 2015;14:1741-1747.

21 Martiskainen M, Pohjasvaara T, Mikkelsson J, Mäntylä R, Kunnas T, Laippala P, et al: Fibrinogen gene promoter -455 A allele as a risk factor for lacunar stroke. Stroke 2003;34:886-891. 